
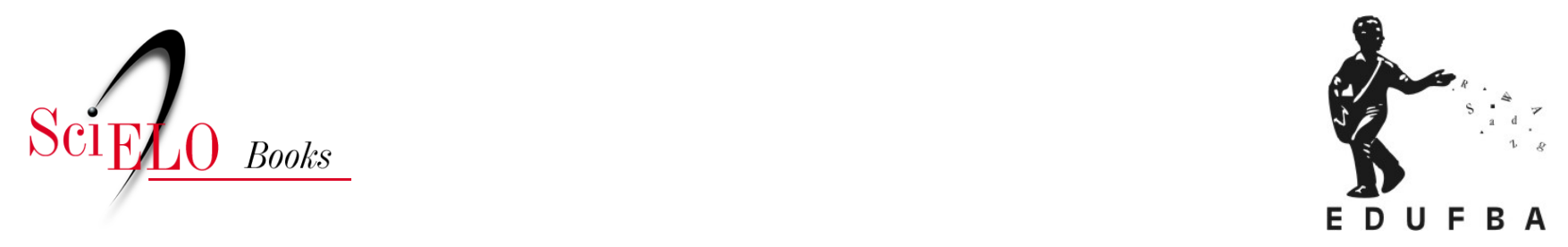

\title{
Capoeira regional como patrimônio cultural brasileiro
}

\author{
Hellio Campos
}

\section{SciELO Books / SciELO Livros / SciELO Libros}

CAMPOS, H. Capoeira regional como patrimônio cultural brasileiro. In: Capoeira regional: a escola de Mestre Bimba [online]. Salvador: EDUFBA, pp. 72-77. ISBN 978-85-232-1727-3. Available from: doi: $10.7476 / 9788523217273.0008$. Also available in ePUB from:

http://books.scielo.org/id/p65hq/epub/campos-9788523217273.epub.

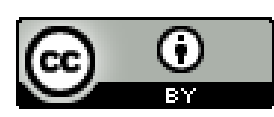

All the contents of this work, except where otherwise noted, is licensed under a Creative Commons Attribution 4.0 International license.

Todo o conteúdo deste trabalho, exceto quando houver ressalva, é publicado sob a licença Creative Commons Atribição 4.0.

Todo el contenido de esta obra, excepto donde se indique lo contrario, está bajo licencia de la licencia Creative Commons Reconocimento 4.0. 


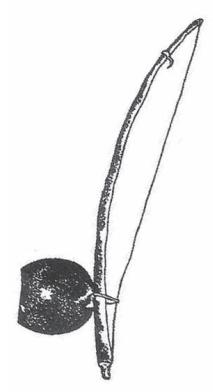

Capoeira regional como patrimônio cultural brasileiro

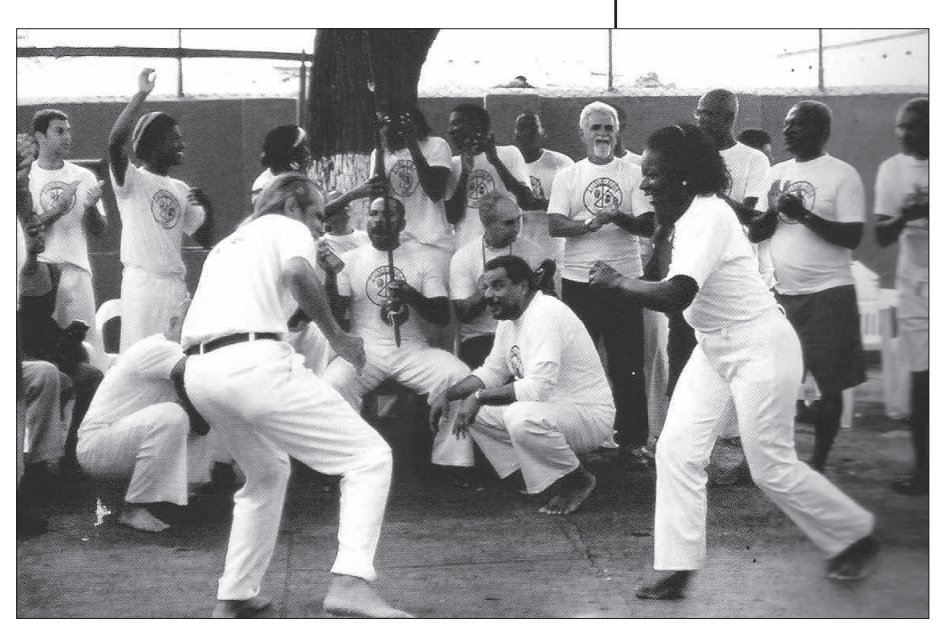



ala-se muito da capoeira como uma manifestação cultural brasileira. Aqui preten-
demos discutir a capoeira, o patrimônio, a cultura e trazer à tona a Constituição Brasileira para elucidar o que seja o patrimônio cultural brasileiro e os bens de natureza material e imaterial.

O patrimônio está historicamente associado à noção de sagrado, de herança, de memória do indivíduo, de bens familiares. No século XVIII, através de uma nova visão, uma visão moderna de história e de cidade, concebe-se a idéia de um patrimônio comum a um grupo social, definidor de sua identidade.

A palavra patrimônio tem vários significados. O mais comum é compreendê-la como um conjunto de bens que uma pessoa ou entidade possuem. Se pensarmos numa dimensão territorial, o patrimônio passa a ser um conjunto de bens que dentro de seus limites de competência pertencem a uma unidade administrativa. Patrimônio também pode ser entendido como um complexo de bens, materiais ou não, uma riqueza moral, cultural e intelectual. Assim, podemos definir o patrimônio nacional como um conjunto de bens que estão inseridos num determinado sítio.

Rodrigues diz que o patrimônio nacional supera os limites de uma região, é uma referência comum a todos que habitam o mesmo território, resultando das tradições, costumes nacionais, língua nacional, história nacional e, dessa maneira, "o patrimônio passou a ser, assim, uma construção social de extrema importância política" (2002, p. 16).

Distinguimos o patrimônio em duas grandes vertentes:

a) patrimônio natural; e

b) patrimônio cultural.

O patrimônio natural diz respeito às riquezas naturais de um país: seu solo, subsolo, florestas, rios, jazidas etc. Quanto ao patrimônio cultural, inicialmente sinônimo de obras monumentais, obras de arte consagradas, propriedades luxuosas, associadas às classes dominantes e pertencentes à sociedade civil e política, esse conceito vem sendo ampliado à medida que se revisa o conceito de cultura.

Sabe-se que a cultura é ampla e dinâmica e pode ser observada por diferentes óticas. Lima, referindo-se a cultura como um processo, ressalta que "cultura pode significar a dimensão da sociedade incluindo vários aspectos do conhecimento". Cita que, em antropo- 
logia, "cultura não é simplesmente um referente que marca uma hierarquia de civilização, mas a maneira de viver total de um grupo, sociedade, país ou pessoa" (2000, p. 16).

Para Schneider, "[...] cultura é um sistema de símbolos e de significados. Compreende categorias ou unidades e regras sobre relações e modos de comportamento" (apud LARAIA, 2000, p. 36).

Anselmo Júnior entende cultura como "algo humano" relacionado com a "simplicidade de um povo, nas suas formas de expressão, modos de criar, fazer e viver" (2004, p. 6).

Cultura está intimamente ligada ao saber: podemos considerar a cultura como o lado majestoso do saber. Um povo que cultua sua cultura é um povo forte que encontra ou reencontra suas raízes e os caminhos que o levam a seu destino, simbolizado no eterno e inatingível laço que liga o futuro ao passado.

Cultura também pode ser entendida como um conjunto de valores materiais e espirituais criados pela humanidade no curso de sua história. Para Sodré, a cultura é um fenômeno social que concebe e recorda o estado de uma sociedade em uma determinada etapa histórica de progresso, técnica, experiência de produção e de trabalho, instrução, educação, ciência, literatura, arte e instruções que lhe correspondem (1972, p. 3). Podemos, então, afirmar, baseados em conceitos modernos, que cultura são sistemas fundados em comportamentos socialmente transmitidos.

A cultura brasileira é muito rica e está centrada nas dimensões continentais, na mistura das raças, na existência de culturas diversas, numa população indígena ainda em "estado primitivo", nos afro-descendentes, nos imigrantes e pessoas que acompanham os padrões de modernidade das sociedades mais avançadas, o que faz com que o Brasil tenha um contraste cultural bem peculiar.

O homem, no sentido biológico, é capaz de sofrer adaptações. Essas adaptações representam modos de vida diferenciados de cada indivíduo e da humanidade, o que inclui tecnologias, organizações econômicas, padrões, grupamentos sociais, organização política, crenças, artes, práticas religiosas e tudo o que diz respeito à construção do homem.

Para Barreto, o patrimônio cultural é entendido como as obras de arte, dança e música, porém ele ressalta, ainda, que os seres humanos não produzem apenas obras de arte, mas, sobretudo, ciência, sabedoria, máquinas, remédios, história, vestuário, receitas de cozinha, formas de relacionamento, hábitos, usos e costumes (2002, p. 12).

Na atualidade, existe um consenso de que o conceito de patrimônio cultural extrapola as manifestações artísticas, mas corresponde a todo o fazer humano, que depende das concepções de cada época e também sofre modificações segundo as circunstâncias do momento.

Para Santos, "a abrangência conceitual na abordagem do patrimônio cultural está relacionada com a retomada da própria definição antropológica da cultura" como "tudo o que caracteriza uma população humana" ou como "o conjunto de modos de ser, viver, pensar e falar de uma dada formação social". Segue dizendo: "todo conhecimento que uma sociedade tem de si mesma, sobre outras sociedades, sobre o meio material em que vive e sobre sua própria existência" (apud SANTOS, 1999); acrescentamos ainda as formas de 
expressão simbólica desse conhecimento no âmbito das idéias, da construção de objetos e das práticas rituais e artísticas.

A Organização das Nações Unidas para Educação, Ciência e Cultura (UNESCO) entende cultura como o "patrimônio dos valores e conhecimentos teóricos e práticos que estruturam a identidade de um povo, assim como o veículo da energia e das idéias criativas pelas quais os povos podem enriquecer e renovar sua identidade e entrar em contatos com outras culturas"1. A cultura compreende também todo um "conjunto de características distintas, espirituais e materiais, intelectuais e afetivas, que caracterizam uma sociedade ou um grupo social [...]", englobando, "além das artes e letras, os modos de viver, os direitos fundamentais dos seres humanos, os sistemas de valor, as tradições e as crenças".

Castro, reportando-se ao amparo do Estado às manifestações culturais, cita que "a Constituição de 1988 criou toda uma série de novas 'linhas de frente' na questão da preservação do patrimônio cultural". Afirma ainda que "não por serem inovadoras", pois "praticamente tudo o que consta nela já era feito, em maior ou menor grau pelos órgãos da área da cultura e outros" (2005, p. 1). Entretanto, na sua ótica, o suporte de proteção passa a ter um caráter inovador, por criar obrigações legais do Estado para que este aja com mais responsabilidade, de maneira mais ativa e eficaz em diversas frentes.

As "linhas de frente" às quais se reporta na preservação da memória de um ou dos chamados "grupos formadores" da nacionalidade brasileira é a população afro-descendente. O que se pretende é valorizar um grupo que historicamente faz parte da construção, em todos os aspectos, deste Brasil, resistindo à opressão da escravidão.

As manifestações da cultura popular brasileira são asseguradas hoje pela Constituição da República Federativa do Brasil, através da Seção II, que trata da Cultura. Em seu Art. 215 observa que o Estado garantirá a todos o pleno exercício dos direitos culturais e acesso às fontes da cultura nacional, apoiará e incentivará a valorização e a difusão das manifestações culturais.

Sobre o patrimônio cultural, a Constituição se refere da seguinte maneira, no seu Art. 216:

\footnotetext{
Constituem patrimônio cultural brasileiro os bens de natureza material e imaterial, tomados individualmente ou em conjunto, portadores de referência à identidade, à ação, à memória dos diferentes grupos formadores da sociedade brasileira, nos quais se incluem:

I as formas de expressão;

II os modos de criar, fazer, viver;

III as criações científicas, artísticas e tecnológicas;

IV as obras, objetos, documentos, edificações e demais espaços destinados às manifestações artístico-culturais;

V os conjuntos urbanos e sítios de valor histórico, paisagístico, artístico, arqueológico, paleontológico, ecológico e científico.
}

A Constituição refere-se claramente sobre os bens de natureza imaterial. A UNESCO reconhece o Patrimônio Cultural e Imaterial como de importância vital para garantir, não só os aspectos físicos que constituem a cultura de um povo, mas, sobretudo, aqueles contidos 
nas tradições, no folclore, nos saberes, nas línguas, nas festas, nos folguedos e em diversos outros aspectos e manifestações, transmitidos oral ou gestualmente, recriados coletivamente e modificados ao longo do tempo. A essa porção intangível da herança cultural dos povos dá-se o nome de patrimônio cultural imaterial.

Para muitos povos, especialmente as minorias étnicas e os povos indígenas, o patrimônio imaterial é uma fonte de identidade e carrega em seu âmago a sua própria história.

Os valores filosóficos, as formas de pensar, as expressões linguísticas, representadas nas tradições orais e nas demais manifestações culturais, constituem o fundamento da vida comunitária. No mundo atual, em constante mutação e de crescente interação global, a revitalização da herança tradicional assegura a sobrevivência da diversidade de culturas dentro de cada sítio comunitário, contribuindo sobremaneira para o alcance de um mundo plural.

A Capoeira Regional insere-se nesse contexto, por representar uma manifestação popular rica em movimento, musicalidade e expressão corporal bem aceita pelo povo por ser oriunda do segmento afro-brasileiro.

A capoeira também é uma manifestação multirreferenciada, podendo ser reconhecida e praticada como arte, luta, esporte, folclore, educação, arte marcial, lazer, cultura e filosofia de vida.

Para Santos, "la Capoeira fue um instrumento de resistencia com características guerreras, frente a los aspectos de ordem social, político, económico o cultural, que, debido al régimen escravista, impedía al negro cualquier oportunidad de ascender dentro de la sociedad brasileña, al que solo quedaba la fuga, fundamental para su libertad" (1997, p. 118).

Barbieri, expressando-se sobre o capoeira e a capoeira, diz tratar-se de "uma peculiaridade da existência-do-homem-no-mundo, da relação dialética que se estabelece entre o homem, o mundo e as coisas". Aprofunda o seu pensamento, fundamentado na corporeidade do capoeira como uma forma integrada de como o homem vive no mundo, experimentando as "diversas formas de ser significativo a si mesmo e aos outros e, assim, vivenciar a sua humanidade" (2003, p. 132).

Nestor Capoeira, citando a concepção de alguns autores sobre o que seja a capoeira, destaca Dias Gomes, consagrado dramaturgo e novelista brasileiro, com o seguinte conceito:

Capoeira é luta de dançarinos. É dança de gladiadores. É duelo de camaradas. É jogo, é bailado, é disputa simbiose perfeita de força e ritmo, poesia e agilidade. Única em que os movimentos são comandados pela música e pelo canto. A submissão da força ao ritmo. Da violência à melodia. A sublimação dos antagonismos. Na capoeira os contendores não são adversários, são camaradas. Não lutam, fingem lutar. Procuram genialmente dar visão artística de um combate. Acima de um espírito de competição, há um sentido de beleza. O capoeira é um artista e um atleta, um jogador e um poeta (1998, p. 105).

Para Santos, "ao contribuir na formação cultural das pessoas, a capoeira faz com que elas conheçam a realidade contada através de protagonistas que formam parte dessa cultura e não através de livros publicados pela classe que sempre exerceu o poder" (2002, p. 191).

Mais uma vez, Nestor Capoeira relata que a capoeira em sua história se comporta como um bom capoeirista no "jogo da vida": ginga, dá reviravoltas súbitas e inesperadas, 
fica de cabeça para baixo, engana, finge que vai, mas não vai, cai e levanta, sai de rolê e dá a volta por cima (1998, p. 107).

Entendendo ser a capoeira um patrimônio cultural relevante para o mundo, o Diretor Geral do Instituto do Patrimônio Artístico e Cultural da Bahia (IPAC), Julio Santana Braga, em 22 de dezembro de 2004, baseado no artigo 40, da Lei Estadual no 8.895, de 16 de dezembro de 2003, que institui normas de proteção e estímulo à preservação do patrimônio cultural do Estado da Bahia, tornou público, através de Notificação Pública, o processo de registro da capoeira, como Patrimônio Imaterial, através de sua inscrição em livro especial do patrimônio imaterial, mantido pelo IPAC e denominado "Livro do Registro Especial das Expressões Lúdicas e Artísticas" (Lei citada, art. 5, inc.VIII).

Esse importante passo do IPAC vem ao encontro da Recomendação sobre a Salvaguarda da Cultura Tradicional e Popular, proposta pela UNESCO, em 1989. Essa proposição tem sua aplicação ao redor do mundo e visa fornecer instrumentos legais para a identificação, preservação e continuidade dessa forma de patrimônio, assim como de sua disseminação.

${ }^{1}$ In: http://www.unesco.org.br/areas/cultura/cultura/mostra_documento. 